\title{
Effect of Different Concentrations of Red Palm Olein and Different Vegetable Oils on Antioxidant Enzymes in Normal and Stressed Rat
}

\author{
Eqbal M. A. Dauqan, Aminah Abdullah and Halimah Abdullah Sani
}

Additional information is available at the end of the chapter

http://dx.doi.org/10.5772/48272

\section{Introduction}

Oxygen radicals are continuously formed in all living organisms, with deleterious effects that lead to cell injury and death. Production of oxidative species occurs under physiological conditions at a controlled rate, but it is dramatically increased in conditions of oxidative stress. Reactive oxygen species (ROS) is a term which encompasses all highly reactive, oxygen-containing molecules, including free radicals [1, 2]. Free radicals are an atom or molecule that bears an unpaired electron and is extremely reactive, capable of engaging in rapid change reaction that destabilize other molecules and generate many more free radicals $[3,4]$. Vitamin E compounds (tocopherols and tocotrienols) are well recognized for their effective inhibition of lipid oxidation in food and biological systems [5, 2]. Carotenoids can act as primary antioxidants by trapping free radicals or as secondary antioxidants by quenching singlet oxygen. In foods, carotenoids usually act as a secondary antioxidant. Beta-carotene is found in many foods that are orange in color [6].

Stress plays a significant role in the development of atherosclerotic heart disease (AHD) [7]. A stressful condition leads to the excessive production of free radicals which results in oxidative stress an imbalance in the oxidant per antioxidant system [8]. Under normal conditions, there is a natural defense system provided by several enzymes such as superoxide dismutase (SOD), catalase (CAT) and glutathione peroxidase (GSH-Px) which performs a vital role for detoxification of free radicals. The use of antioxidant rich food or antioxidant food supplements became immensely popular since many diseases have been associated with oxidative stress [9]. Antioxidant enzyme such as superoxide dismutase (SOD) is an important radical superoxide scavenger and it plays an important role in cell protection [10, 2]. Therefore, this CAT or SOD enzyme are very good biochemical markers of stress and their increased activity may attest to a potential for remediation [11]. Inherent 
antioxidant defense systems consisting of enzymes, such as catalase (CAT), and superoxide dismutase (SOD), an antioxidant nutrients may participate in coping with oxidative stress. As antioxidant enzymes have an important role in the protection against free radical damage, a decrease in the activities or expression of these enzymes may predispose tissues to free radical damage [12].

Red palm oil (RPO) is extracted from the oil palm (Elaeis guineenis) fruit [13, 14]. It derives its red colour from the high content of alpha- and beta-carotenes, which can make up $0.08 \%$ $(\mathrm{w} / \mathrm{w})$ of the crude oil [13]. Red palm oil is the oil obtained before refining and the characteristic colour of RPO is due to the abundance of carotenoids $(500-700 \mathrm{mg} / \mathrm{L})$ in the crude oil $[15,16]$. Most people are not aware of the fact that many different kinds of vitamin $\mathrm{E}$ occur in nature and that some forms of vitamin $\mathrm{E}$ are more beneficial than others. Red palm oil contains vitamin E tocotrienols, which acts as a super-antioxidant and the carotenoids in red palm oil also act as antioxidants [17].

Corn oil presents a relatively high concentration of polyunsaturated fatty acids (PUFA).Due to the high levels of unsaturation these lipids are highly susceptible to free radical oxidative reactions, giving rise to the formation of lipid peroxides. Many investigations suggest that a large number of polyunsaturated fatty acids produces more lipid peroxides and may have mutagenic activity $[18,19]$.

Coconut oil is a colorless to pale, brownish yellow oil [20]. It is the major sources of saturated fat apart from palm kernel. They are the only natural sources of lauric oil available to the world market. Coconut oil is the principal cholesterol-raising fat because it contains large amounts of lauric (C: 12: O) and myristic (C: 14: 0 ) acids [21]. Therefore the objective of this study is to investigate the effect of different concentration of red palm olein and different vegetable oils on antioxidant enzymes in normal and stressed rats.

\section{Problem statement}

Due to the importance of the role of antioxidants in protection against the oxidative stress which lead to many dangerous diseases such as heart diseases and cancer thus this study was done to investigate the effect of natural antioxidants particularly vitamin $\mathrm{E}$ and beta carotene in red palm olein on antioxidant enzymes and compared the results with four different vegetable oils in normal and stress conditions of rats.

\section{Effect of different vegetable oils on antioxidant enzymes in normal and stressed rats}

The evaluated red palm olein (RPO) samples consisted of carotenes (576 ppm), vitamin E $(>800 \mathrm{ppm})$ and free fatty acids $(0.045 \%)$ provided by Carotino SDN BHD company and palm olein (PO) (Seri Murni), corn oil (CO) and coconut oil (COC) were obtained commercially. For the first group the test diet was prepared by mixing RPO with normal commercial rat pellet to contain $5 \%, 10 \%$ and $15 \%$ of the red palm olein (RPO). The $5 \%$ diet was prepared by adding $5 \mathrm{~g}$ RPO to $95 \mathrm{~g}$ rat pellet, and mixed manually and the diets were 
then left to absorb the RPO at room temperature overnight and stored at $20^{\circ} \mathrm{C}$ before the feeding trial was conducted. Similar process was conducted with $10 \%$, and $15 \%$ RPO. For second group the test diet was prepared by mixing vegetable oils with normal commercial rat pellet to contain $15 \%$ of the vegetable oils. The $15 \%$ diet was prepared by adding $15 \mathrm{~g}$ $\mathrm{RPO}, \mathrm{PO}, \mathrm{CO}$ or COC to $85 \mathrm{~g}$ rat pellet, and mixed manually and the diets were then left to absorb the vegetable oils at room temperature overnight and stored at $20^{\circ} \mathrm{C}$ before the feeding trial was conducted.

Normal (N) group: Rats were maintained under standard laboratory conditions and fed with respective diet till the completion of the experiment.

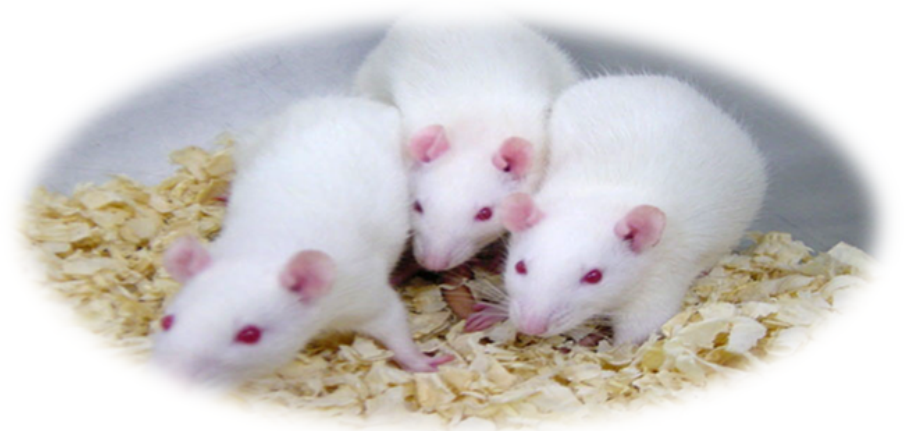

Figure 1. Normal rats

Stress (S) group: Rats were restrained by placing them in individual nylon plastic bag for 3 $\mathrm{hr} /$ day for one week before killing. Under these conditions rat were fed with respective diet, till the completion of the experiment.

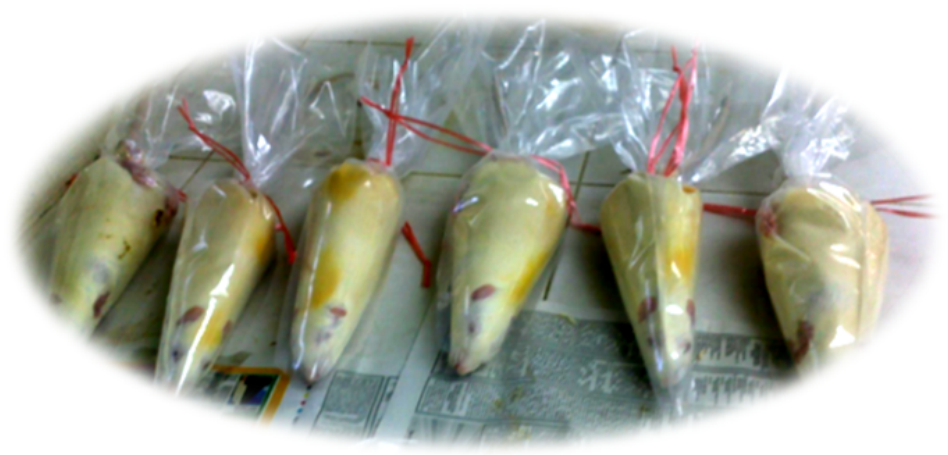

Figure 2. Stressed rats

One hundred and eighty Sprague Dawley male rats each weighing between $170-250 \mathrm{~g}$ and approximately 80 days old were obtained from the animal house of the Faculty of Science and Technology, Universiti Kebangsaan Malaysia. They were divided into three groups. 
The first group contains 78 rats were divided into 13 groups of 6 rats per group. The rats were fed ad libitum with commercial rat's pellet containing different concentrations of red palm olein (RPO) for 2, 4 and 8 weeks. The second group contains 66 Sprague Dawley male rats which were randomly divided into 11 groups of 6 rats per group and were treated with $15 \%$ of RPO, palm olein (PO), corn oil (CO), coconut oil (COC) and control groups for 4 and 8 weeks. The third group contains 36 Sprague Dawley male rats which were randomly divided into six groups of 6 rats per group ( 3 normal groups and 3 stressed groups) and were treated with $15 \%$ of RPO and PO for 4 weeks. At the end of the experiment, after 2, 4 or 8 weeks of treatment the feeding of rats was stopped and the rats were fasted for 18 hours. They were anesthetized using chloroform. The liver was removed immediately and was washed it with $\mathrm{NaCl}$ solution. It was stored at $-80^{\circ} \mathrm{C}$ until analyzed.

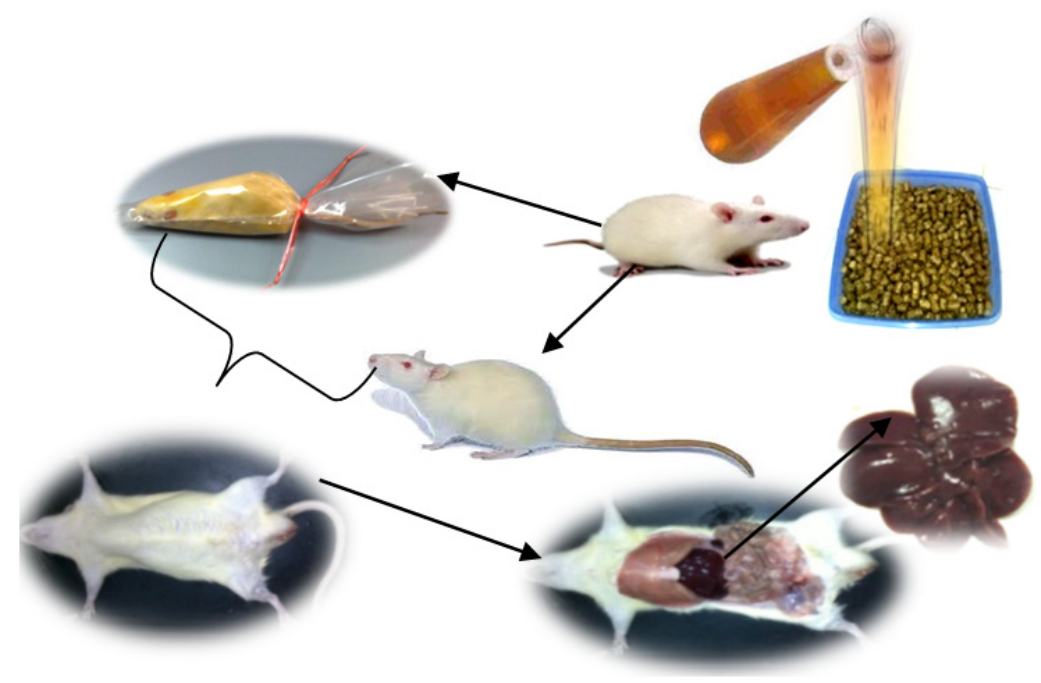

Figure 3. Procedure for collecting liver from rat

A $0.2 \mathrm{~g}$ sample of liver was cut to small pieces. Tissue was suspended in $2 \mathrm{ml}$ of $50 \mathrm{mM}$ phosphate buffer ( $\mathrm{pH} 7.4$ ), and was homogenized using a mixer at top speed for $3 \mathrm{~min}$. Afterwards, the homogenate was centrifuged at $20000 \mathrm{~g}$ for $25 \mathrm{~min}$. In this process the temperature was maintained at $4 \mathrm{C}^{0}$ during the homogenization process. Phosphate buffer was prepared based on Aebi's method [22]. Phosphate buffer $50 \mathrm{mM}$, PH 7.0: dissolve (a) $6.81 \mathrm{~g} \mathrm{KH}_{2} \mathrm{PO}_{4}$, and (b) $8.90 \mathrm{~g} \mathrm{Na}_{2} \mathrm{HPO}_{4} .2 \mathrm{H}_{2} \mathrm{O}$ in distilled water and make up to $100 \mathrm{ml}$ each mix solution (a) and (b) in proporation 1:1.5 (v/v).

Enzyme activity of catalase (EC.1.11.1.6) was determined based on Aebi's method [22]. Catalase activity was measured at $22^{\circ} \mathrm{C}$ by monitoring the decomposition of hydrogen peroxide. The reaction mixture consisted of $2.0 \mathrm{~mL}$ of the liver homogenate suspended in phosphate buffer ( $50 \mathrm{mM}, \mathrm{pH} 7.0)$, and $1.0 \mathrm{~mL}$ of hydrogen peroxide solution $(30 \mathrm{mM})$. The absorbance was recorded for 2 minutes at $240 \mathrm{~nm}$ immediately after adding hydrogen 
peroxide solution. Catalase activity was expressed as moles of hydrogen peroxide reduced $/ \mathrm{min} / \mathrm{mg}$ protein.

Activity superoxide dismutase (EC.1.6.4.2) was assayed based on the method of Marklund and Marklund [23]. Superoxide dismutase activity was determined at $22^{\circ} \mathrm{C}$ by using the

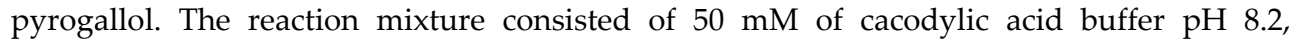
containing $1 \mathrm{mM}$ EDTA, $300 \mu \mathrm{l}$ of liver homogenate, $300 \mu \mathrm{l}$ of $0.2 \mathrm{mM}$ pyrogallol. The absorbance was recorded for 3 minutes at $420 \mathrm{~nm}$ immediately after adding the pyrogallol solution. Superoxide dismutase activity was expressed as units of SOD/minute/mg protein.

Protein concentrations were determined based on the Lowry method [24]. To $0.1 \mathrm{~mL}$ of sample or standard was added $0.1 \mathrm{~mL}$ of $2 \mathrm{~N} \mathrm{NaOH}$ and hydrolyze at $100^{\circ} \mathrm{C}$ for $10 \mathrm{~min}$ in boiling water bath. The hydrolysate was cooled to room temperature and added $1 \mathrm{~mL}$ of freshly mixed complex-forming reagent. Let the solution stand at room temperature for 10 min. After that, $0.1 \mathrm{~mL}$ of Folin reagent was added using a vortex mixer, and let the mixture stand at room temperature for 30-60 min. The absorbance was recorded at $750 \mathrm{~nm}$. Figure 4 showed the standard curve of absorbance which was plotted as a function of initial protein concentration and used it to determine the unknown protein concentrations.

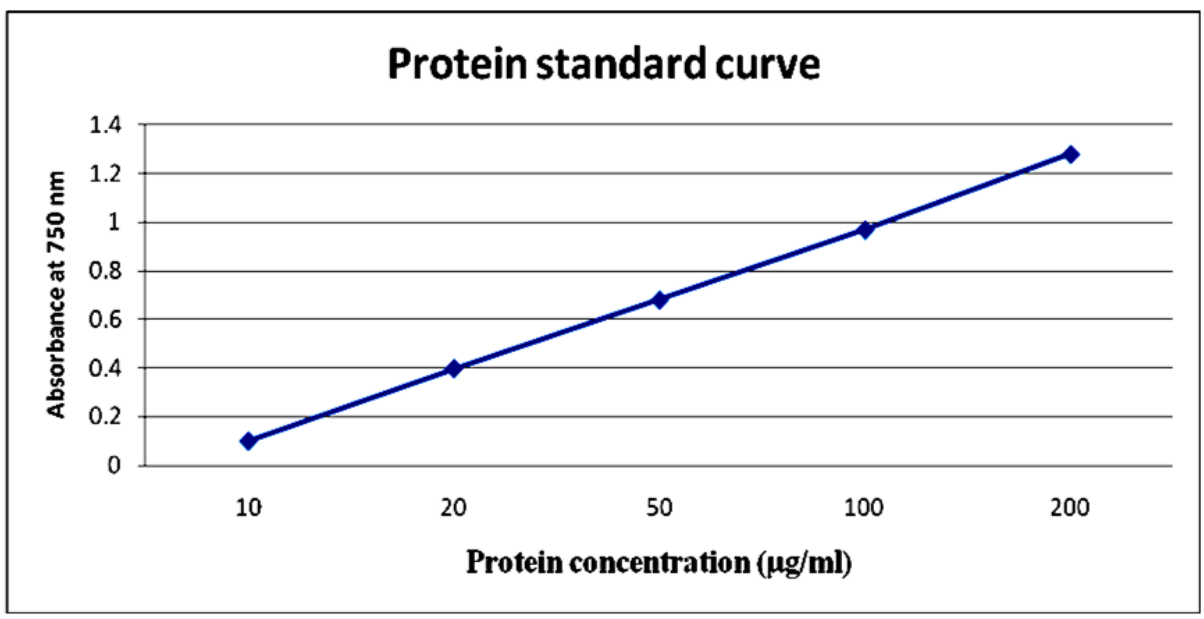

Figure 4. Protein standard curve

\subsection{Effect of different concentrations of red palm olein on antioxidant enzyme of normal rat liver}

Antioxidant is an important part of a cells defense against free radical damage. Antioxidant enzymes, in particular, constitute a major part of this defense [25]. It is evident from earlier work that different concentrations RPO have differential effects on the activities of antioxidant enzymes [10]. Figures 5, 6 and 7 showed the results of catalase activity at different concentrations of RPO (5\%,10\% and 15\%) for different times $(2,4$ and 8 weeks) of treatment. After 2 weeks there was no significance difference $(p \geq 0.05)$ between the control 
group and $10 \%$ and $15 \%$ concentrations of RPO while at $5 \%$ there was an increased in the catalase activity. At 4 weeks there was no significance difference $(p \geq 0.05)$ between the control group and different concentrations groups (5\%,10\%, and 15\%) of RPO. At 8 weeks there was no significance difference between the control group and $5 \%$ group while at $10 \%$ and $15 \%$ there was decreasing of the catalase activity but there was no significance difference $(\mathrm{p} \geq 0.05)$.

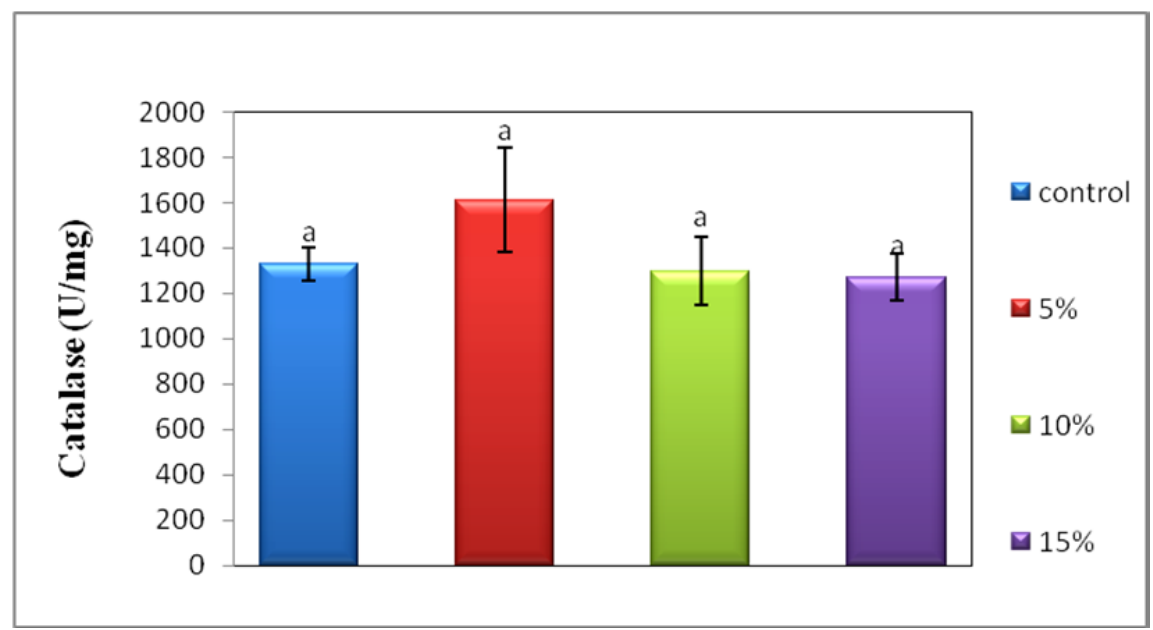

Figure 5. The catalase activity $(\mathrm{u} / \mathrm{mg})$ in liver of rats fed with different type of red palm oil $(0 \%, 5 \%$, $10 \%$ and $15 \%)$ for 2 weeks. Bars are mean \pm SEM $(n=6)$, no significantly different $(p>0.05)$.

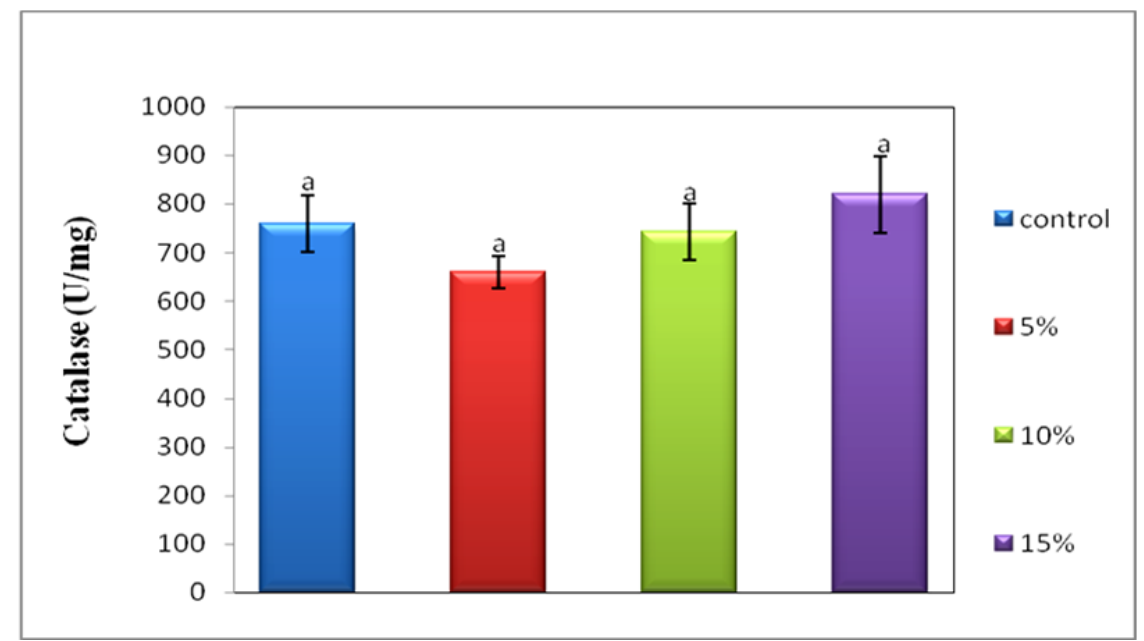

Figure 6. The catalase activity $(\mathrm{u} / \mathrm{mg})$ in liver of rats fed with different type of red palm oil $(0 \%, 5 \%$, $10 \%$ and $15 \%)$ for 4 weeks. Bars are mean \pm SEM $(n=6)$, no significantly different $(p>0.05)$. 


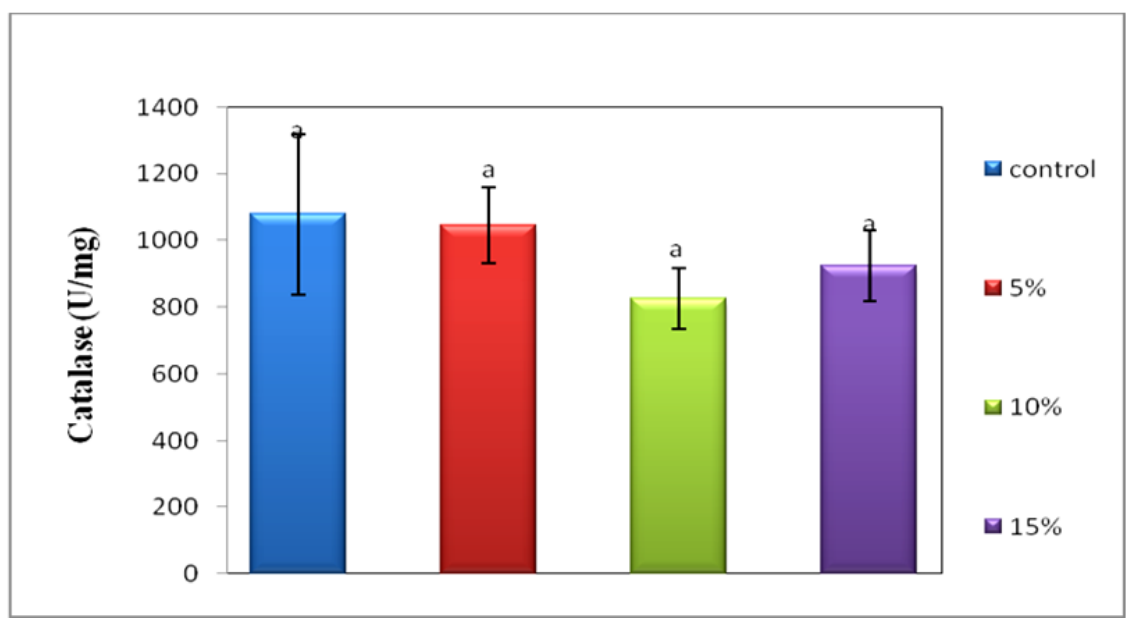

Figure 7. The catalase activity $(\mathrm{u} / \mathrm{mg})$ in liver of rats fed with different type of red palm oil $(0 \%, 5 \%$, $10 \%$ and $15 \%)$ for 8 weeks. Bars are mean \pm SEM $(n=6)$, no significantly different $(p>0.05)$.

Figures 8,9 and 10 showed the results of SOD activity at different concentration of RPO (5\%, $10 \%$ and $15 \%)$ for different times $(2 \mathrm{w}, 4 \mathrm{w}$ and $8 \mathrm{w})$ of treatment. After 2 weeks there was an increased in SOD activity at 5\% while there was a decreased in SOD activity at $10 \%$ and $15 \%$ groups. However, there were no significance differences $(\mathrm{p} \geq 0.05)$ among these groups. On the contrary at 4 weeks the SOD activity increased with increasing duration of treatment in all concentrations compared to the control group. There was no significant $(p \geq 0.05)$ increased in SOD activity at 15\% concentration of RPO.

At 8 weeks there was no significant difference $(\mathrm{p} \geq 0.05)$ between the control group and all treatment groups of RPO except there was decreased in SOD activity at $15 \%$ of RPO. Therefore, after 4 weeks the activity of SOD was significantly higher $(p \leq 0.05)$ at $15 \%$ of RPO dietary group compared to the control group but the increase in the $10 \%$ of RPO dietary group was not statistically significant. On the other hand, there was a significantly decreased $(\mathrm{p}<0.05)$ in $15 \%$ of RPO dietary group after 2 and 8 weeks.

The results of this study showed that $15 \%$ treatment of RPO which contain $\beta$-carotene and vitamin $\mathrm{E}$ for 4 weeks may enhance the antioxidant enzyme (SOD) defence system. These results thus suggest that a combination of carotenoids and vitamin E (tocopherol and tocotrinol) in the RPO has an important role in the protection against free radical damage. Red palm oil contains the highest concentration of tocotrienols compared to other vegetables or plants and the tocotrienols can be 40-60 times more potent as anti-oxidant than tocopherols [26]. Tocotrienols are free radical scavenging antioxidants, however, only the $\alpha$ isomer has considerable biological antioxidant activity. It is therefore not surprising that there are relatively very few studies on their antioxidative effects in oils and fats $[2,26]$.

Although a few of studies explicitly show the effects of vitamin $\mathrm{E}$ on the activities of antioxidant enzymes, there is no consensus on what might be the responses of antioxidant 
enzymes to vitamin E, partly because of different feeding behavior and other ecological conditions [27].

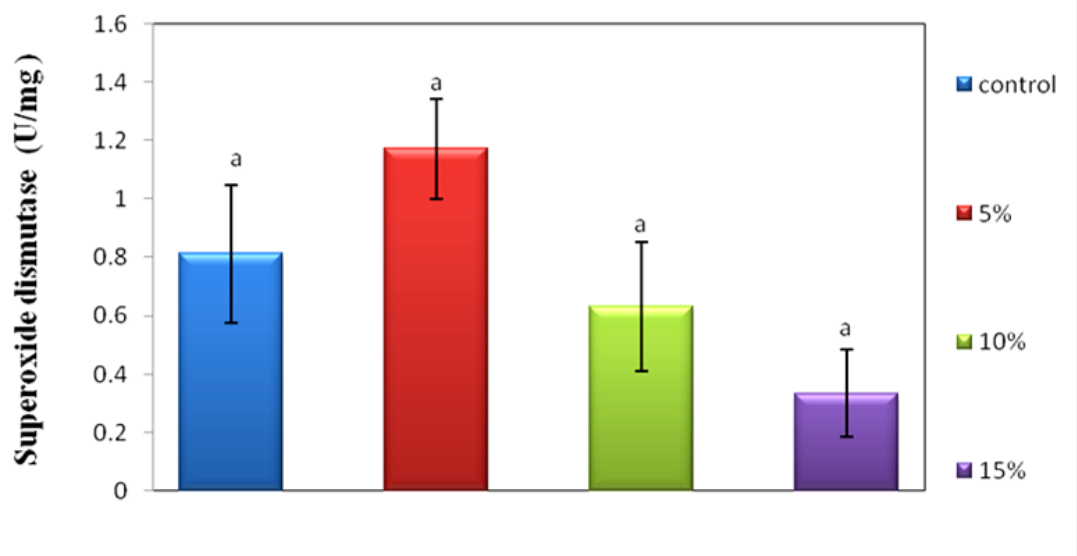

Figure 8. The superoxide dismutase (SOD) activity $(\mathrm{u} / \mathrm{mg})$ in rat liver fed with different type of red palm oil $(0 \%, 5 \%, 10 \%$ and $15 \%)$ for 2 weeks. Bars are mean \pm SEM $(n=6)$, no significantly different ( $p>0.05)$ at all treated groups with RPO.

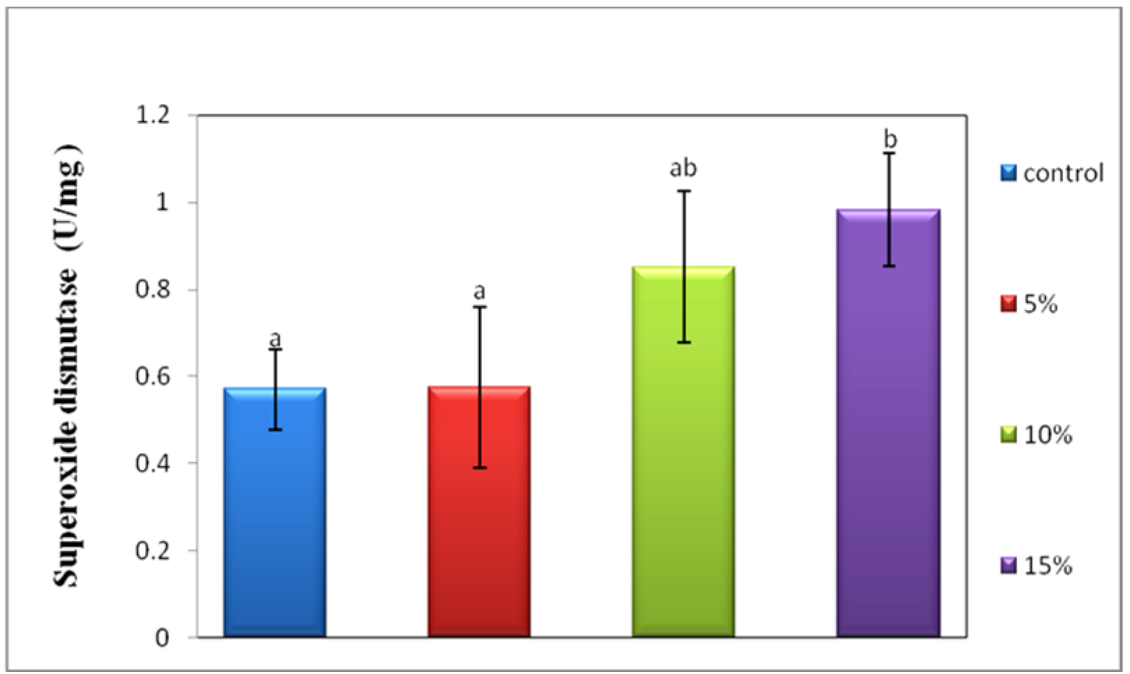

Figure 9. The superoxide dismutase (SOD) activity $(\mathrm{u} / \mathrm{mg})$ in rat liver fed with different type of red palm oil $(0 \%, 5 \%, 10 \%$ and $15 \%)$ for 4 weeks. Bars are mean \pm SEM $(n=6)$, no significantly different $(\mathrm{p}>0.05)$ at $5 \%$ and $10 \%$, significantly different $(\mathrm{p}<0.05)$ at $15 \%$ 


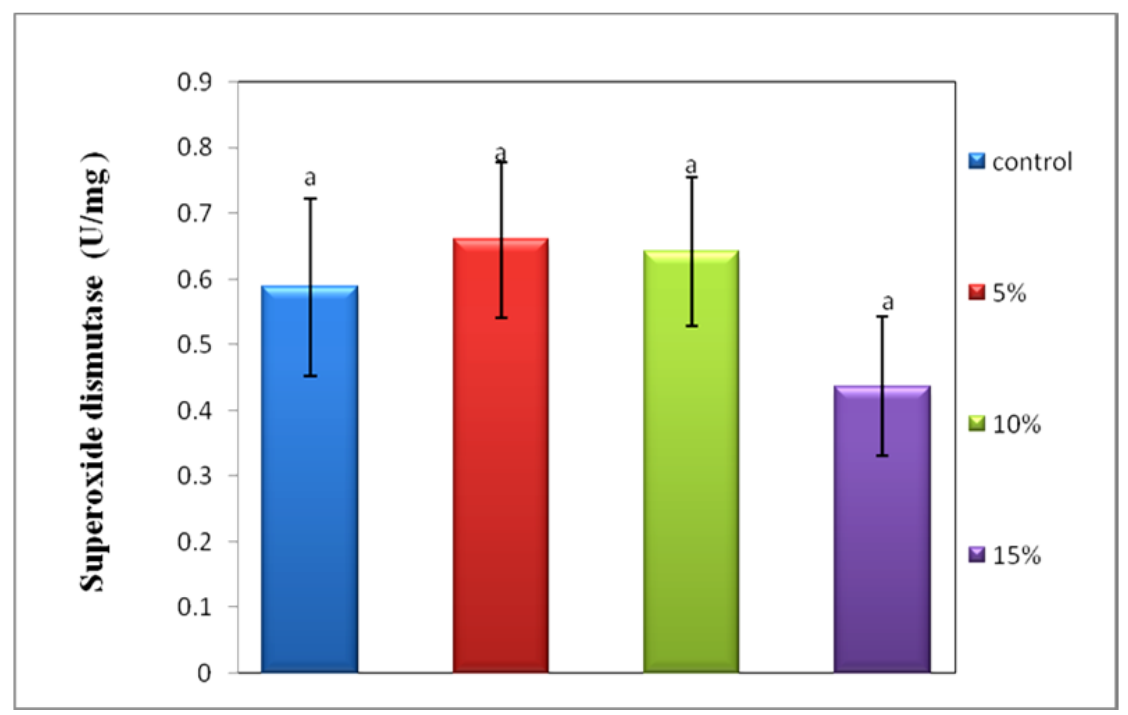

Figure 10. The superoxide dismutase (SOD) activity $(\mathrm{u} / \mathrm{mg})$ in rat liver fed with different type of red palm oil $(0 \%, 5 \%, 10 \%$ and $15 \%)$ for 8 weeks. Bars are mean $\pm \operatorname{SEM}(n=6)$, no significantly different $(\mathrm{p} \geq 0.05)$.

\subsection{Effect of four different vegetable oils (RPO, PO, CO and COC) on antioxidant enzyme activity of normal rat liver}

The results of CAT activity at different vegetable oils (RPO, PO, CO and COC) for different times ( 4 and 8 weeks) of treatment are summarized in Figures 11 and 12. After 4 weeks there was no significance different $(\mathrm{p} \geq 0.05)$ between control group and different vegetable oils treated groups while at 8 weeks there was significance decreased $(p \leq 0.05)$ in $P O, C O$ and COC groups compared to control group but the CAT liver sample was no significant different $(\mathrm{P} \geq 0.05)$ between control group and RPO group.

Several studies have illustrated that RPO is a rich cocktail of lipid-soluble antioxidants such as carotenoids ( $\alpha$ - and $\beta$-carotene, lycopenes), vitamin $\mathrm{E}$ (in the form of $\alpha-, \beta-, \delta$ - tocotrienols and tocopherol) [27]. Red palm oil has $17,500 \mathrm{mg}$ of $\beta$-carotene per $100 \mathrm{~g}$, and 28,000 $\mathrm{mg}$ of $\alpha$-carotene per $100 \mathrm{~g}$ for a total of 6,140 retinol equivalents per $100 \mathrm{~g}$. Thus, it has good potential for routine diets with enrichment carotenoids [28]. Red palm fruit oil (RPO) contains about 15 times more carotenes than that present in the same weight of carrots, and 44 times that of leafy vegetables [29]. Palm oil is a rich source of vitamin E, having both tocotrienols and tocopherols [30,31]. 


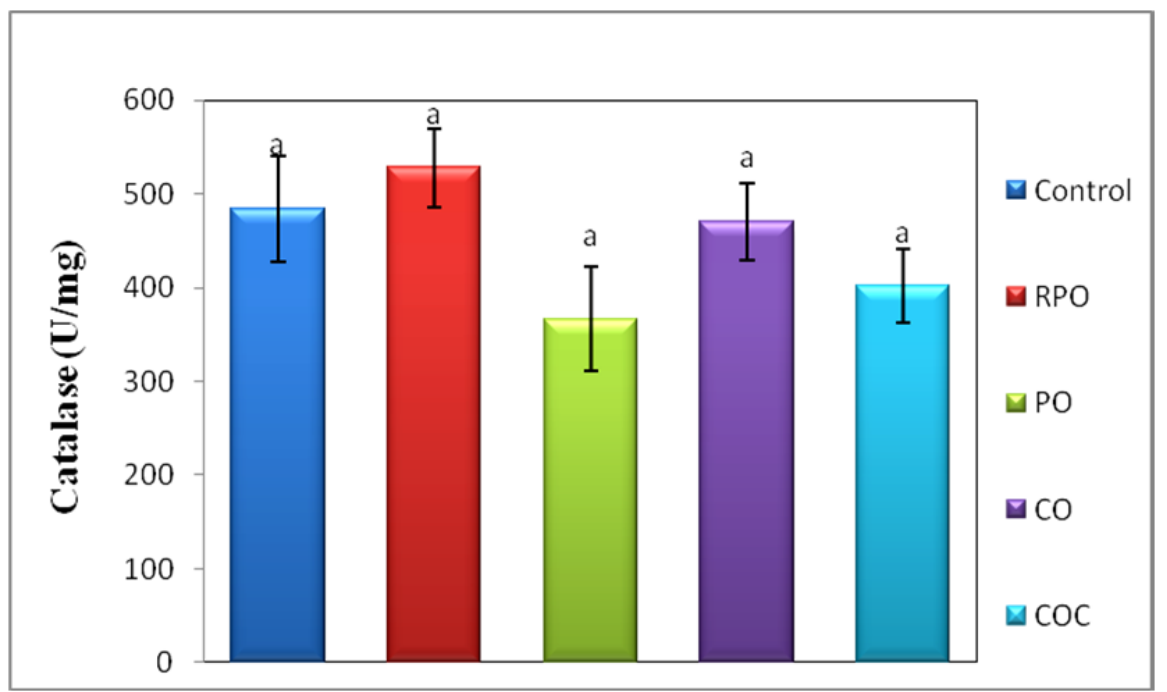

Figure 11. The catalase activity (CAT) in rat liver fed with different vegetable oils for 4 weeks. Bars are mean $\pm \operatorname{SEM}(\mathrm{n}=6)$, no significantly different $(\mathrm{p} \geq 0.05)$.

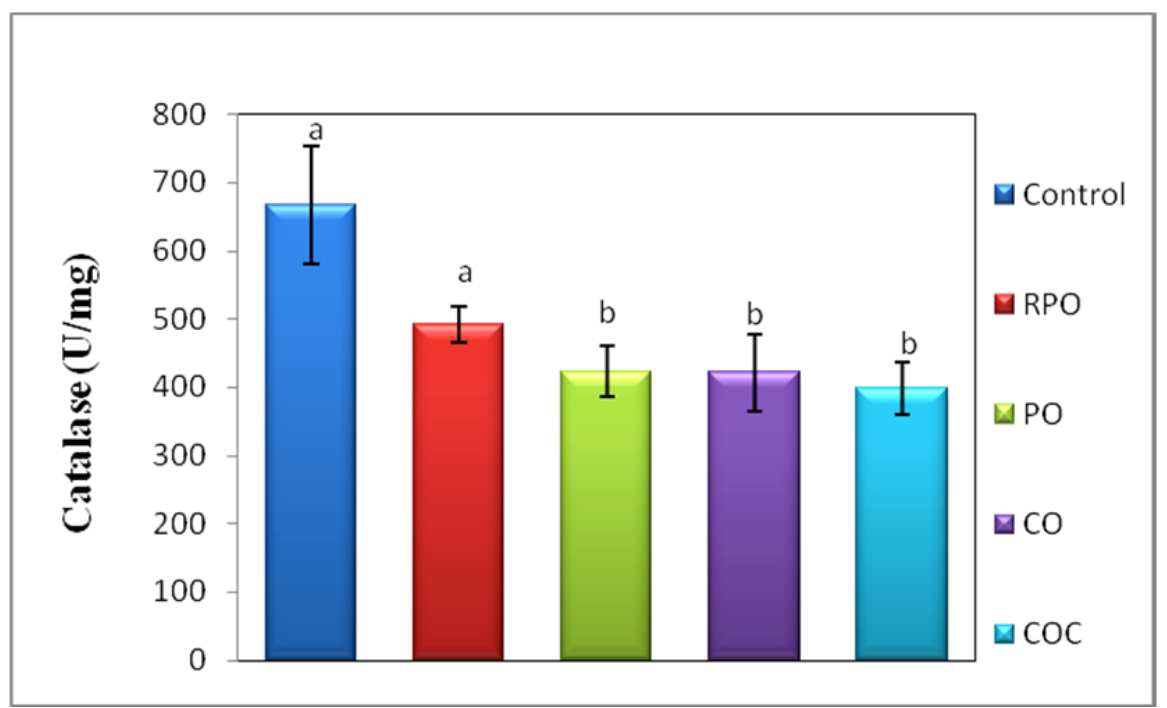

Figure 12. The catalase activity (CAT) in rat liver fed with different vegetable oils for 8 weeks. Bars are mean $\pm \operatorname{SEM}(n=6)$, different alphabet an each bar indicate significant different $(P \leq 0.05)$. 
The results of SOD activity at different vegetable oils (RPO, PO, CO and COC) for different times (4 and 8 weeks) of treatment are summarized in Figures 13 and 14. After 4 and 8 weeks there was no significance different $(p \geq 0.05)$ between control group and different vegetable oils treated groups.

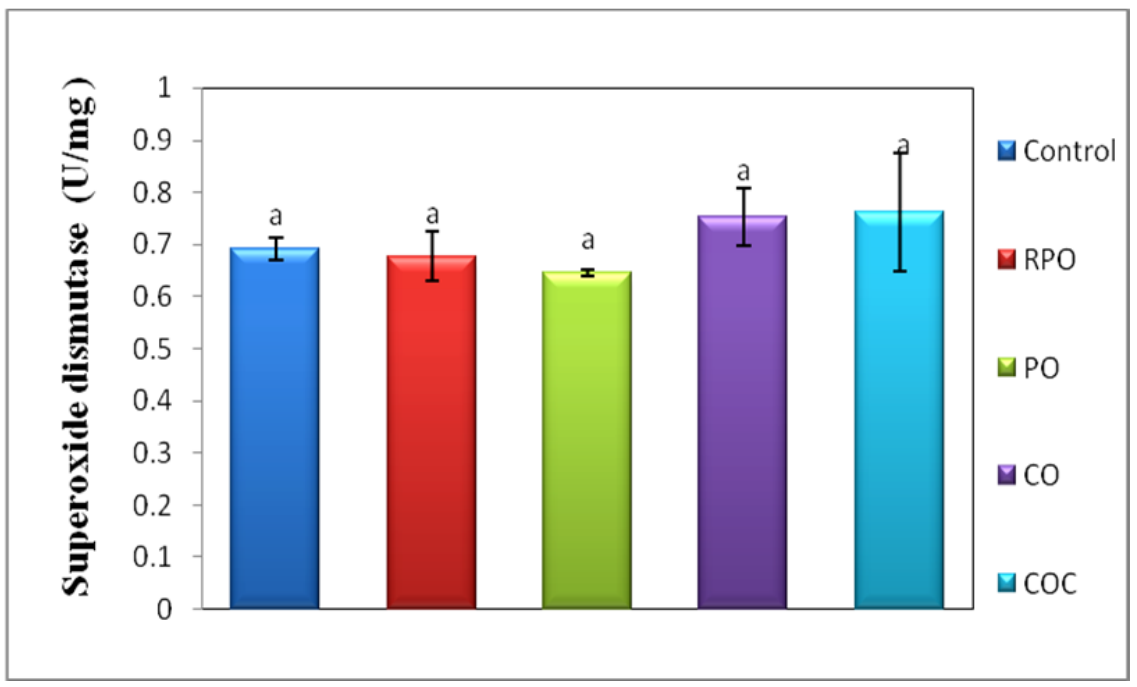

Figure 13. The superoxide dismutase (SOD) activity in rat liver fed with different vegetable oils for 4 weeks. Bars are mean \pm SEM $(n=6)$, no significantly different $(p \geq 0.05)$.

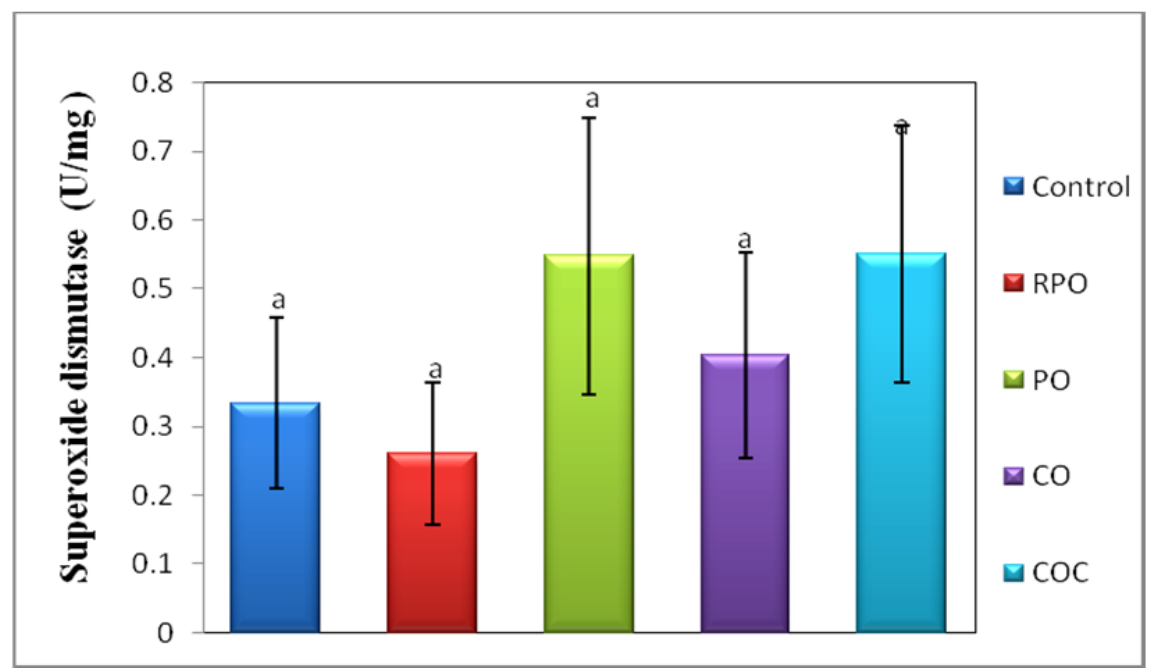

Figure 14. Mean superoxide dismutase (SOD) activity in rat liver fed with different vegetable oils for 8 weeks. Bars are mean \pm SEM $(n=6)$, no significantly different $(\mathrm{p} \geq 0.05)$. 
The results from the present study, after different times, showed that under sedentary conditions, ad libitum feeding of RPO. There was no significant difference in level of the catalase in the control group and different concentration groups of RPO treatment. Mazlan et al. [32] reported that the catalase is the slowest of the antioxidant enzymes to respond to an increased level of free radicals. On the other hand, the CAT activity in rat liver treated with $\mathrm{PO}, \mathrm{CO}$ and $\mathrm{COC}$ groups was decreased compared to control group.

This study finding was similar to that of Rathnagiri et al. [33] who reported that there were no statistically significant differences between control fed rats with respect to SOD activity in the corn oil. The effect of COC on antioxidant enzyme in this study was not in agreement with Anitha and Lokesh [34] who found that COC increased significantly of SOD activity in the liver but Anitha and Lokesh [34] used coconut oil with groundnut oil or olive oil instead of COC. Vitamins directly scavenge ROS and regulate the activities of antioxidant enzymes. Among them, vitamin $\mathrm{E}$ has been recognized as one of the most important antioxidants [27].

This probably involves their actions as antioxidants, reducing the level of free radicals and hence free radical damage. Antioxidant enzymes, such as superoxide dismutase (SOD) play a major role in removing the Reactive Oxygen Species (ROS) [11]. At this time point, it is suggested that different experimental period might lead to different result about the effect of dietary vitamin $\mathrm{E}$ on the activities of antioxidant enzymes [27]. In the present study, the 2 weeks period in which this experiment was carried out may be insufficient to witness any change in the activity of this enzyme.

In addition to this, Yazar and Tras [35] reported that prior induction of ROS could cause an increase intracellular SOD activity. Hence first induction of ROS may cause changes in SOD activity and then SOD activity may return to the normal level. SOD enzyme, together with CAT, protects cells against damage caused by free radicals and hydrorlipoperoxides [36]. According to Catherine et al. [37] vitamin E work synergistically to decrease the multiplication of free radicals. Vitamin E inhibits the production of lipid hydroperoxide. However, reduced SOD activities may also indicate increased lipid peroxidation endproducts like acid thiobarbituric [38]. Intricately linked to lipid peroxidation are antioxidant enzymes such as SOD and catalase. As a defense against reactive free radicals, the body produces antioxidant enzymes which help to mop them up [39].

As red palm olein was shown to reduce MDA production and increase SOD in 15\% group for 4 weeks, it would spare the retina from damage. This effect of palm oil may be related to the ability of $\beta$-carotene to quench free radicals and prevent tissue damage [40]. The relatively lower cholesterol level in treated rats and higher antioxidant enzyme activity could be viewed as potentially beneficial for the health of the user population in humans [41].

Presence of high amount of unsaturated fatty acids may be the reason for the low antioxidant enzyme activities of some vegetable oils fed rat since polyunsaturated fatty acids (PUFA) deteriorates the antioxidant status due to their liability to become highly oxidized. Feeding oils high in polyunsaturated fatty acids (PUFA) results and increase the oxidative stress since PUFA are highly susceptible to peroxidation than monounsaturated and saturated fatty acid [42]. 


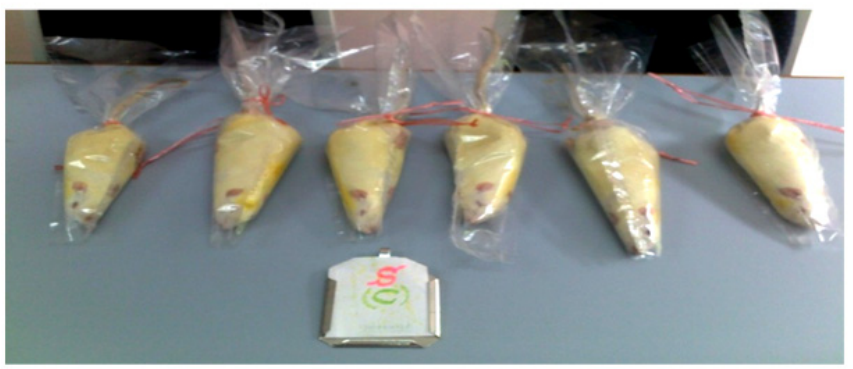

(A) Stressed control group

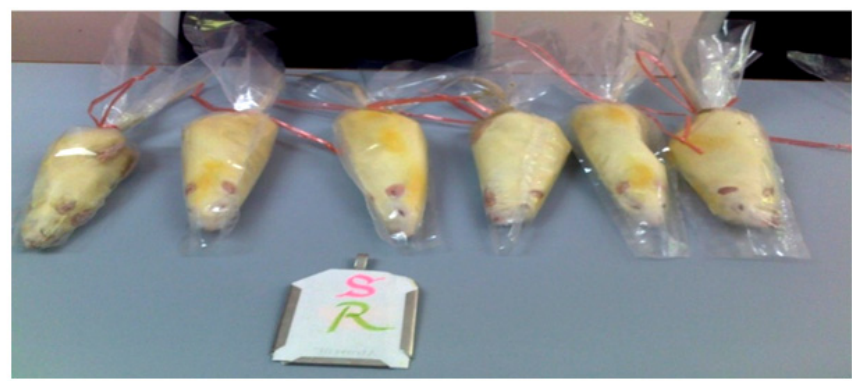

(B) Stressed red palm olein group

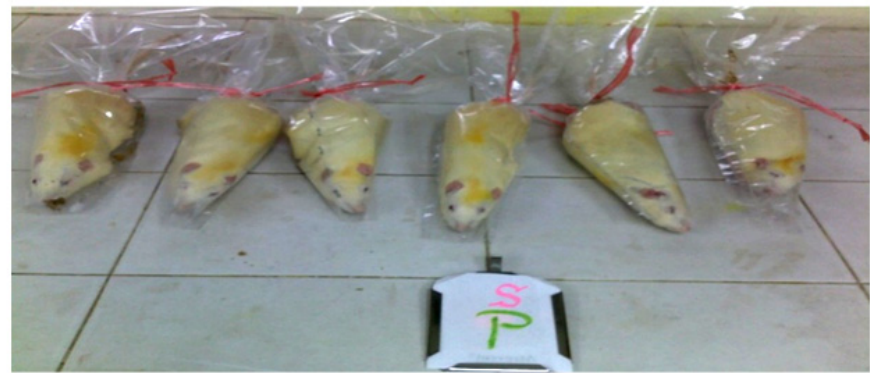

(C) Stressed palm olein group

Figure 15. (A) Stressed control group, (B) Stressed red palm olein group, (C) Stressed palm olein group

\subsection{Effect of red palm olein and palm olein on antioxidant enzymes in stressed rat liver}

Figure 16 shows the results of CAT activity in liver samples of normal and stressed rats that were treated with $15 \%$ of RPO and PO for 4 weeks of treatment. After 4 weeks, there was no significant difference $(\mathrm{P} \geq 0.05)$ between control group and $15 \% \mathrm{RPO}$ and $\mathrm{PO}$ normal groups whereas there was significant decreased $(\mathrm{P} \leq 0.05)$ between control group and $15 \% \mathrm{RPO}$ stressed group and there was significantly higher $(\mathrm{P} \leq 0.05)$ in $15 \%$ PO stressed group than 
the control group. This study finding were similar to that of Benson and Kshama [7] who reported that the CAT activity in RPO group has shown significant decrease compared to $\mathrm{PO}$ and RPO groups under stress conditions.

Many recent studies emphasize the important role of reactive oxygen species (ROS) in the pathogenesis of various liver diseases. Stress known to increase oxidative stress in the major organs including the liver [42].

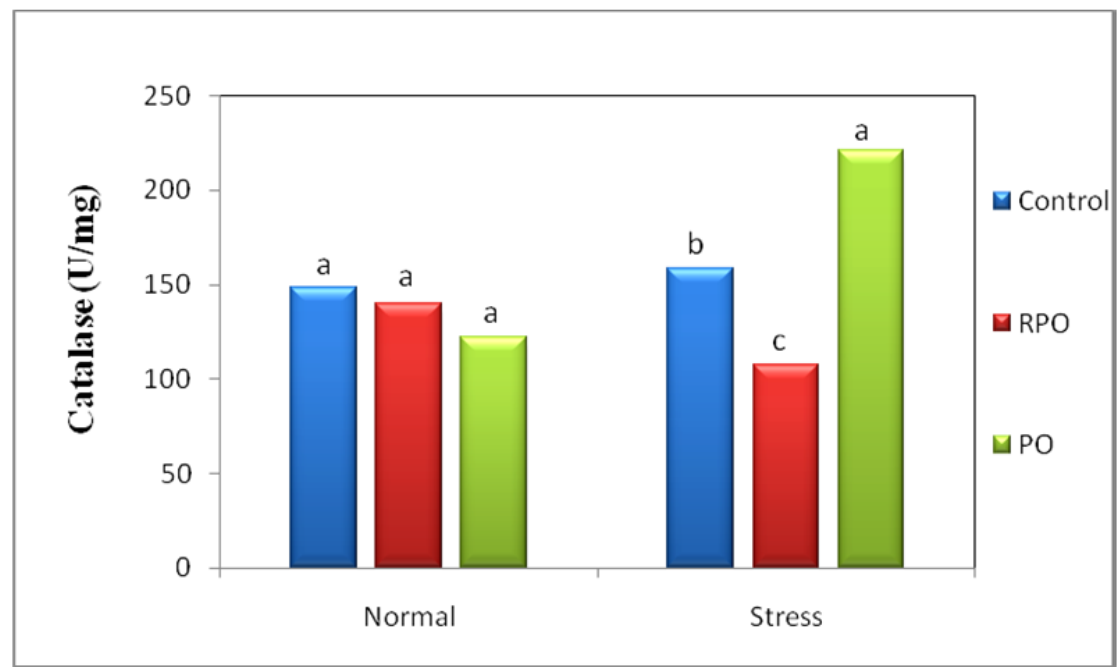

Figure 16. The catalase (CAT) activity in normal and stressed rats fed with red palm olein and palm olein for 4 weeks. Bars are mean $\pm S E M(n=6)$, different alphabet an each bar indicate significant different $(\mathrm{P} \leq 0.05)$.

Figure 17 shows the results of SOD activity in liver samples of normal and stressed rats that were treated with $15 \%$ of RPO and PO for 4 weeks of treatment. After 4 weeks, there was significantly lower $(\mathrm{P} \leq 0.05)$ in $15 \% \mathrm{RPO}$ and $\mathrm{PO}$ normal and stressed groups than the control group. Vitamin $\mathrm{E}$ is a major antioxidant vitamins found in the cell and can prevent cell damage through its activity as a free radical chain breaker [43]. Free radicals have been implicated in the etiology of large number of major diseases. They can adversely alter many crucial biological molecules leading to loss of form and function. Such undesirable changes in the body can lead to diseased conditions. Antioxidants can protect against the damage induced by free radicals acting at various levels [43].

$\beta$-Carotene has received considerable attention in recent times as a putative chain-breaking biological antioxidant and its ability to interact with free radicals such as peroxyl radicals and to scavenge and quench singlet oxygen is well documented [44]. Defense mechanisms against free radical-induced oxidative damage include the catalytic removal of free radicals and reactive species by factors such as catalase (CAT), superoxide dismutase (SOD) and reduction of free radicals by electron donors, Such as vitamine E (tocopherol and tocotrienol) [45]. 


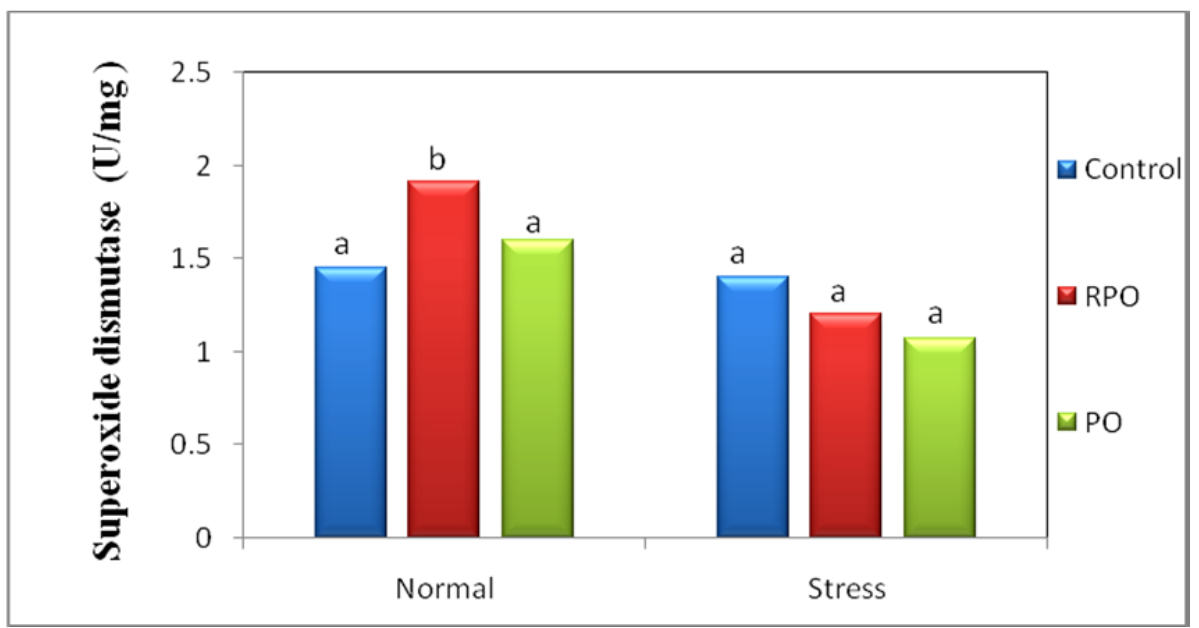

Figure 17. The superoxide dismutase (SOD) in normal and stressed rats fed with red palm olein and palm olein for 4 weeks. Bars are mean $\pm \operatorname{SEM}(n=6)$, different alphabet an each bar indicate significant different $(\mathrm{P} \leq 0.05)$.

\section{Conclusion}

In conclusion, palm oil may offer some protection to liver of the treated rats by reducing free radicals damage, as well as increasing SOD. The present study shows no significant difference in level of catalase in control group and different concentration groups of RPO treatment but after 4 weeks $15 \%$ of RPO was enhanced the SOD activity level in rat liver. It can be concluded that the effect of different concentrations of RPO appear to depend on the different period of treatment. The current study shows no significant difference in level of catalase in control group and RPO group but the treated rat liver with $\mathrm{PO}, \mathrm{CO}$ and COC groups were the lowest and it were significantly lower than control group. After 4 weeks of treatment, $15 \%$ of RPO enhances the SOD activity level in rat liver.These results could be due to the high content of vitamin $\mathrm{E}$ (tocopherols and tocotrienols) and $\beta$-carotene in red palm olein. Treatment with 15\% RPO and PO diets did not affect the CAT activity after 4 weeks of treatment under normal condition while there was decreased in CAT activity with RPO and increased with PO under stress conditions. Additionally, the results in RPO group showed that higher SOD activity compared to PO and control groups under normal conditions while there were no significant difference $(\mathrm{P} \leq 0.05)$ in SOD between the control group and treated groups under stress conditions.

\section{Author details}

Eqbal M. A. Dauqan and Halimah Abdullah Sani

School of Biosciences and Biotechnology, Faculty of Science and Technology,

Universiti Kebangsaan Malaysia, Bangi Selangor, Malaysia 
Aminah Abdullah

School of Chemical Sciences and Food Technology, Faculty of Science and Technology,

Universiti Kebangsaan Malaysia, Bangi Selangor, Malaysia

\section{Acknowledgement}

This work was supported by the Organization for Women in Science for the Developing World (OWSDW) and the research was funded by UKM-GUP-NBT-27-103, UKM-HEJIMIndustri-16-2010 and UKM OUP-NBT-29-139/2011 We grateful thank to caroteno sdn bhd Malaysia for providing red palm olein sample

\section{References}

[1] Sapakal, V. D., Shikalgar, T. S., Ghadge, R. V., Adnaik, R. S., Naikwade, N. S. \& Magdum, C. S. 2008. In vivo screening of antioxidant profile: A review. Journal of Herbal Medicine and Toxicology 2(2): 1-8

[2] Eqbal, D., Halimah, A. S., Aminah, A.\& Zalifah M. K. 2011. Effect of different concentrations of red palm olein on antioxidant enzymes activity of rat liver. African Journal of Biotechnology 10(22): 4651-4655

[3] Sulekha, M., Satish, Y., Sunita, Y., Rajesh, K. N. 2009. Antioxidants: A Review. Journal of Chemical and Pharmaceutical Research 1(1):102-104

[4] Shiv, K. 2011. Free radicals and antioxidants: Human and food system. Advances in Applied Science Research 2(1): 129-135

[5] Kang, K. R., Cherian, G. \& Sim, J. S. 2001. Dietary palm oil alters the lipid stability of polyunsaturated fatty acid-modified poultry products. Poultry Science 80:228-234

[6] Hamid, A. A. , Aiyelaagbe, O. O., Usman, L. A., Ameen, O. M. \& Lawal, A. 2010. Antioxidants: Its medicinal and pharmacological. African Journal of Pure and Applied Chemistry 4(8): 142-151

[7] Benson, M. K. \& Kshama D. 2009. Influence of $\omega-6 / \omega$-3rich dietary oils on lipid profile and antioxidant enzymes in normal and stressed rat. Indian journal of experimental biology 47: 98-103

[8] Ramasundaram, S. Narayanaperumal, J. P., Aundaramaglingam, M., Govindarajulu S. N. \& Rathinasamy S. 2007. Effect of Triphala on oxidative stress and on cell-mediated immune response against noise stress in rats. Molecular and Cellular Biochemistry 283(1-2): 67-74

[9] Akpinar, D., Yargicoglu, P., Derin, N., Aliciguzel, Y. \& Agar, A. 2008. The effect of lipoic acid on antioxidant status and lipid peroxidation in rats exposed to chronic restraint stress. Physiol. Res. 57: 893-901

[10] Zullyt, B. Z., Ricardo, G. A., Dailen, G., NelsonMerino, F. H. R., Silvia, M. C., Yaima, A. G. \& Siegfried, S. 2007. Antioxidant mechanism is involved in the gastroprotective effects of ozonized sunflower oil in ethanol-induced ulcers in rats. Mediat. Inflamm. 10: 1-6.

[11] Malgorzata, K. \& Edward, A. G. D. 2003. Antioxidant enzymes in paraquat and cadmium resistant cell lines of horseradish. Biol. Lett. 40(1): 61-69

[12] Jaya, T. V., Poomchai, A., Neera, S. \& Gabriel, F. 1998. Effects of dietary n-6 and n-3 lipids on antioxidant defense system in livers of exercised rats. J. Am. Coll. Nutr. 17: 586-594 
[13] Monica, O., Ingrid, V. \& Noel, W. S. 2006. Household usage of and recipe creation with condiment sauces based On red palm oil: Exploring the potential for targeted micronutrient delivery to different family members. Journal of Oil Palm Research 18: 181188

[14] Edem, D. O. \& Akpanabiatu, M. I. 2006. Effects of palm oil-containing diets on enzyme activities of rats. Pak. J. Nutr. 5(4): 301-305

[15] Edem, D. O. 2009. Haematological and histological alterations induced in Rats by Palm Oil-Containing Diets. Eur. J. Sci. Res. 32: 405-418

[16] Wanna, A. \& Yaakob, C. 2010. A rapid method for determination of commercial $\beta$ carotene in RBD palm olein by Fourier transform infrared spectroscopy. Asian Journal of Food and Agro-Industry 3(04): 443-452

[17] Azizan, B. A. 2006. Development of HPLC analysis for detection of lycopene on tomato and palm oil, University College of Engineering \& Technology Malaysia

[18] Michael, J. P. \& David, F. W. 1975. Monosomic analysis of fatty acid compostion in embryo lipids of Zea Maysl. Genetics 81: 277-286

[19] Valls, M. G. V., Mun, P., Saez, G. T. \& Cabo, J. R. Effect of corn oil and vitamin E on the oxidative status of adipose tissues and liver in rat. Food Chemistry 81(2): 281-286

[20] Cecille, P., Cecilia, J., Rody, S., Felix, E., Punzalan, \& Pepito, P. 2010. The effect of virgin coconut oil on lipid profile and fasting blood sugar: A phase i clinical trial. Philippine Journal of Internal Medicine 48(2):1-6

[21] Akpanabiatu, M. I., Umoh, I. B., Eyong1, E. U. \& Udoh F. V. 2005. Influence of nauclea latifolia leaf extracts on some hepatic enzymes of rats fed on coconut oil and noncoconut oil meals. Pharmaceutical Biology 43(2):153-157

[22] Aebi, H. 1984. Catalase in vitro. Meth Enzymol. 105: 121-126

[23] Marklund, S. \& Marklund, G. 1974. Involvement of the superoxide anione radical in the autoxidation of pyrogallol and convenient assay for superoxide dismutase. Eur. J. Biochem. 47: 469-474

[24] Jakob, H. W. 2009. The Lowry Method for Protein Quantitation. The Protein Protocols Handbook, Third Edition

[25] Arunabh, B., Richard, A. L., Aparna, K., Khaliquz, Z., Dongxu, S. \& Gabriel, F. 2003 Effect of dietary n-3 and n-6 oils with and without food restriction on activity of antioxidant enzymes and lipid peroxidation in livers of cyclophosphamide treated Autoimmune-Prone NZB/W female Mice. J. Am. Coll. Nutr. 22(5): 388-399

[26] Jacques, V. R. 2005. Can red palm oil protect the heart?. Science in Africa(11/2/2011) //www.scienceinafrica.co.za/2005/september/redpalmoil.htm

[27] Jinghua, F. U., Wenbingzhang, K. M., Xiuni, F., Wei, X., Zhiguo, L., Hongming, M. A. \& Qinghui, A. I. 2007. Effects of vitamin E on antioxidant enzyme activitys and fatty acid compositions in juvenile abalone haliotisdiscus hanna ino. Journal of Shellfish Research 26(3):809-814

[28] Radhika, M. S., Bhaskaram, P., Balakrishna, N., Ramalakshmi, B. A. 2003. Red palm oil supplementation: A feasible diet-based approach to improve the vitamin A status of pregnant women and their infants. Food Nutr. Bull. 24: 208-217

[29] Spinnler, B. A. J. 2003. A place for palm fruit oil to eliminate vitamin A Deficiency. Asia Pac. J. Clin. Nutr. 12(3): 369-372 
[30] Kamat, P. J. \& Devasagayam, T. P. A. 1995. Tocotrinols from palm oil as potent inhibitors of lipid peroxidation and protein oxidation in rat brain mitochondria. Neurosci. Lett. 195: 179-182

[31] Kevin, C., Rahamw, B., Keith, I. \& Trevofr, S. 1984. Lipid peroxidation and lipid antioxidants in normal and tumor cells. Toxicol. Pathol. 12: 235-239

[32] Mazlan, M., Abd Halim, F., Mat Top, G. \& Wan, Z. 2002. Effect of vitamin E on plasma malondialdehyde, antioxidant enzyme levels and the rates of wound closures during wound healing in normal and diabetic rats. Asia Pac. J. Clin. Nutr. 11: 448-451

[33] Rathnagiri, P., Douglasr, S., Julia, E. S., Mark H. F., Larry, W. O., Amir, R. \& Amin, A. N. 1998. Increased Lipid Peroxidation \& Impaired Antioxidant Enzyme Function Is Associated With Pathological Liver Injury in Experimental Alcoholic Liver Disease in Rats Fed Diets High in Corn Oil and Fish Oil. Hepatology 27(5): 1317-1323

[34] Anitha, N. \& Lokesh, R. B. 2008. Rats fed blended oils containing coconut oil with groundnut oil or olive oil showed an enhanced activity of hepatic antioxidant enzymes and a reduction in LDL oxidation. Food Chemistry 108: 950-957

[35] Yazar, E. \& Tras, B. 2001. Effects of fluoroquinolone antibiotics on hepatic superoxide dismutase and glutathione peroxidase activities in healthy and experimentally induced peritonitis mice. Revue de Medecine Veterinaire 152: 235-238

[36] Suleyman, K., Handan, G., Yeter, D., Nihatmert, M., Hakkiyoruk, I. \& Tevhide, S. 2007. Studies on serum _-tocopherol, seleniumlevels and catalase activities in lambs with white muscle disease. Bull. Vet. Inst. Pulawy. 51: 281-284

[37] Catherine, J. Field, I. R. Johnson, \& Patricia, D. Schley 2002. Nutrients and their role in host resistance to infection. Journal of Leukocyte Biology71: 16-32

[38] Looi, M. L., Noor Aini, A. H. \& Yasmin, A. M. Y. 2005. Effects of Palmvitee on Status of Superoxide Dismutase and Glutathione Peroxidase in Rat Liver during Aging. Malaysian Journal of Biochemistry and Molecular Biology 12: 21-24

[39] Eriyamremu, G. E., Ojimogho, S. E., Asagba, S. O. \& Osagie, V. E. 2008. Palm oil induced changes in ocular tissue lipid peroxidation, antioxidant enzymes and ATPases of rabbits in cadmium toxicity. Food and Chemical Toxicology 46 3155-3158

[40] Lyn, P. 2000. Beta-carotene: The controversy continues. Alternative Medicine Review 5(6): 530-545

[41] Nandakumaran, M., AL-Sarraf, R. AL-Fadhli, H., AL-Shammari, M., AL-Harmmi, J. \& AL-Saleh, E. 2009. Effect of oral administration of coconut oil on hematological and metabolic parameters in female adult rats. Nutritional Therapy \& Metabolism 27 (4):183-188

[42] Nevin, K. G. \& Rajamohan, T. 2006. Virgin coconut oil supplemented diet increases the antioxidant status in rats. Food Chemistry 99: 260-266

[43] Vaibhav, D. A., Arunkumar, W., Abhijit, M. P. \& Arvind, S. 2011. Antioxidants as immunomodulator: an expanding research avenue. International Journal of Current Pharmaceutical Research 3(1):8-10

[44] Olatunde, F. E. \& George, B. 1999. Antioxidant activity of palm oil carotenes in organic solution: effects of structure and chemical reactivity. Food Chemistry 64: 315-321

[45] Jorge L. \& Maria E. G. 2009. The role of antioxidants and antioxidant-related enzymes in protective responses to environmentally induced oxidative stress. Mutation Research 674: 137-147 